\title{
A New Reflection on the Innovative Content of Marxist Theory Based on the Background of Political Reform
}

\author{
Juanhui Wei \\ School of Political Studies, Xi'an University, 710065
}

Keywords: Background of political reform; Marxism; Theoretical innovation; Contents; New reflection

\begin{abstract}
Marxism is a common science of mankind, but every practical Marxism may have different themes in theoretical innovation. These themes vary widely, but come from the proletarian practice and the innovative development of productive forces. The innovative themes of Marxism exist potentially in the production and life of mankind, which refer to the reform and innovation with the ultimate goal of establishing the future and prosperity of socialism, involving a number of very complicated parts. The innovation of Marxist theory in the new period in China also has its special characteristics. This article hopes to give a reflection on the contents of the Marxist innovative theme in the new period.
\end{abstract}

\section{Introduction}

Although the essence of Marxism is consistent, its processes of advancing with the times are different. It is able to adapt to the development of new times to develop the theoretical innovation system with different characteristics. For the innovation of Marxism, we will firstly face some basic problems, and in the process of solving these problems, we must pay attention to presenting the Marxism's vitality. The vitality of Marxism is given and created in the process of practice, and also plays a fundamental role in practice. We must propose new practical theme, grasp the Marxism, make progress with innovative development, as well as maintain the spiritual state of ideological emancipation on the basis of the Marxist materialist world view, and challenge the wrong opposites, object against dogma and rigidism, and eliminate all obstacles to the development of Marxist innovation.

\section{The Systematic Content of the Subject of Marxist Theoretical Innovation}

The theoretical practice of Marxist innovation involves serialized contents based on innovation, which is a integral system. It is necessary to solve the essential problem of theoretical innovation, which is a process of comprehensive combination of theoretical choice and practice. The choice of direction for Marxism is the focus of the studies by Marxist innovation theorists for a period of time; it is the focus of many theoretical and practical problems. Therefore, it is possible to solve the major problem in the development of Marxist theory. The development of Marxist theory is the basis for solving the main theoretical problems in a certain period of time.

The Development and Practice of Marxist Theory in the New Political Reform. China is currently in the unique context of new political reform, and the vitality of Marxism is given and generated in the process of practice. In China, the Mao Zedong Thought has been conceived in the period of the New Democratic Revolution, and in the process of modernization, Deng Xiaoping Theory draws a perfect blueprint for the reform practice of Marxism in China. Marxist development in China has a very typical development foundation. During the eight decades under the government of Communist Party of China, the Marxism has accumulated a wealth of practical experience and theoretical experience. The major mission of Marxism development, after the birth of the Communist Party of China, is to guide the people to complete the new democratic revolution to complete the reform and practice in new period. After the overthrow of imperialism and the feudalism, the Communist Party of China established a new China with prosperity, democracy, civilization and solidarity. In the course of the construction of new China, countless revolutionary 
martyrs contributed to the reform and innovation in China based on Marxism, combined the universal truth of Marxism with the special national conditions of China and found the ultimate practical and realistic way for reform by liberating China, and establishing revolutionary bases in rural areas where the enemy's control was weak, to encircle the cities from the countryside and ultimately to seize political power. Nowadays, China has been at the forefront of the world and has become an influential country in the world. In the process of adapting to the transition from the new-democratic revolution period to the socialist revolution period, Marxism played a very important role. In the process of using Marxism for socialist transformation of the private ownership of the productive means, we must make full use of Marxism and Leninism, as well as the Mao Zedong Thought and Deng Xiaoping Theory, to realize the rapid development of revolutionary productive forces in the new period of Marxism and socialism.

Innovation of Education Task Content of Marxist Theory-pattern Innovation. The education contents of Marxist theory continuously change in a certain historical period according to different subjects of innovation, and the themes shift on the basis of the original understanding of Marxism and economic and cultural development. In the process of Marxist theoretical innovation, we need to adhere to the dominance and correctness of theoretical education, and then on this basis, realize the total innovation of several sub-themes according to the historical development of different periods. Marxism in the period of the new democratic revolution is mainly to establish a new democratic revolutionary theoretical system suitable for Chinese national conditions, which is a mark of Marxist innovation. In the process of implementing the reform and opening-up policy, combining Marxism and China's economic development, realizing socialism with Chinese characteristics, liberating labor productivity which was necessary for China at that time, and developing the economy are the fundamental task and premise of Marxism development. The process of Marxist theoretical innovation is completely the process of reform and practice. In this process, the necessity of combining Marxist theoretical innovation with the historical background is demonstrated. We need to put forward the question to the original theory under the new conditions, and improve the rationality of the entire theoretical system in the process of continuous modification.

The Succession and Innovation of Subject of Marxist Innovation. Currently, an important goal of China's society is to be able to establish a comprehensive well-off society. In the process of combining Marxism with the economic development of China, the succession and innovation of Marxist innovation subject, in fact, is to solve the problem that under the new economic situation, how to achieve development of China. The development of the subject of Marxist innovation is a common theme for the development of human society. It is hoped that in the process of historical progress, we should deepen the cognition to law for governance of the Communist Party of China and law for socialist construction as well as the law for development of human society according to the objective law of the economic development. The Marxist innovation in the new historical period, in fact, is to emphasize the people's dominant position, emphasize the important role of people in the process of historical development, and deepen the laws for governance of the Chinese Communist Party, emphasizing the basic role of the socioeconomic development in the process of social development with respect to the main body of social development, and emphasizing human development with respect to the purpose of social development. In other words, in the process of innovation and development, we should combine the Marxist scientific outlook on development and five development concepts of human society.

\section{The Source for Practice of Marxist Theory Innovation}

The practice of Marxist theory innovation still originates from the development of socialist market economy. In the course of the development of socialist market economy, people's social practice and the change of development mode of social productive forces have facilitated economic development, and brought about the opinion of seeking truth from facts. Economic foundation determines the superstructure. In the process of economic development, the social spiritual civilization guided by Marxism is also undergoing change, and on this basis, the practice of theory 
innovation breaks the rigid thinking and traditional ideas, hoping to grasp the starting point and growth point of Marxism according to the essence of seeking truth from facts.

The Chinese Proletariat Preserves the Essence of Marxism by Using Dialectical Materialism. Marxism is actually a great combination of philosophy and economic development. Marxist philosophy is, during the development of dialectical materialism and historical materialism, to use dialectical methods to understand the essence and law of social development. Marxism critically inherited the outstanding achievements of human culture. Under the leadership of the Communist Party of China, the Chinese proletariat has used the principle of dialectical materialism and retained the essence of Marxist philosophy in the process of combining it with the development of social practice in China, achieving the organic unity of materialism and dialectics. This kind of advanced philosophy reveals the law of economic and social movement and change of China's reform and development, enabling us to understand the contradiction of many laws of unity and opposite in the process of economic and social development. The current socioeconomic development of China has been facing with the Internet development. In order to break the traditional Marxism influenced and limited by dogmatism and the rigid and stagnant thinking of people, we need to be liberated from the abstract theory to see the benefit of combining Marxism with the characteristics of China in the process of economic development.

The Practice of Marxist Theory Innovation by Proletariat in the New Period. In the new revolutionary period, we should maintain the advanced nature of Marxism, adhere to the guidance of Marxism for socialist construction of China, and use the dialectical materialism to scientifically solve a series of problems in the course of socialist construction of China. In the process of establishing the proletarian organization and the proletarian revolution, we should consider the requirement of socialist modernization construction of China in new historical period, and use different perspectives to concern about Marxism in scientific development and harmonious society to achieve the socialist modernization construction with Chinese characteristics. Especially, as the members of the Chinese Communist Party become younger and younger, we need to grasp the law of Marxism in China, and for all the party members, especially all levels of leading cadres and theoreticians in the party, strengthen the study on innovation in the knowledge-based economy era as well as strengthen their understanding and implementation of Marxism.

\section{Approach for Marxist Innovation in the Socialism Period}

To establish the theme of Marxist theoretical innovation in the new period, we must consider the situation, understand the theme of Marxist innovation and update the theory, confirm the relations between the other countries and regions of the world and the history of China's reform and economic development, and seize the theoretical basis of Marxist innovation in the process of economic development integration in the world. Socialism with Chinese characteristics must proceed from China's national conditions, and we should solve series of problems left over by history which were caused by the rigid ideas. We should combine Marxism with reform and opening-up in China and the people's economic interest and aspirations to firmly develop the theory.

Hold the Clear Stand of Marxist Political Reform and Improve a Series of Theoretical Results. The clear stand of Marxist political reform is to help the new China under the leadership of the Chinese Communist Party to resist the impact of various decadent ideas and political system in the new historical period. As China becomes increasingly powerful, the successors of Marxism in China still adhere to the advanced nature of Marxist political reform, adhere to the leadership of the Chinese Communist Party and the proletarian revolution, as well as insist on serving the people with the fundamental goal of liberation of mankind and human productive forces. The political mobilization and political reform in the new period are manifested in many new forms, and the revolutionary and scientific nature of Marxism is necessary for the political reform. On this basis, the Chinese Communist Party is required to understand the complicated international situation and domestic political situation, understand the new requirements of the reform, emancipate the labor productivity of Chinese people, and promote the political construction and the reform and opening- 
up of China, in order to continue to improve the theoretical results of Marxism, and facilitate the continuous development of Marxist reform in new China.

The Integration of Humanistic Education with the Core Values of Socialism and Marxism. Marxist theory is derived from practice, develops with the development of practice, and is ultimately in turn applied to the practice. On the basis of establishing the dialectical materialist and historical materialist outlook on development, Marxism reveals the law of the process of human society; while the Chinese proletariat hopes to combine this scientific concept of development and the idea of comprehensive and sustainable development, so as to develop Marxism better in the new historical period. The construction of the core value system in China indicates that the socialist core values are the reflection of Marxism development in the new period of China. Carrying forward the traditional Chinese virtues and carrying out socialist humanistic education are the guiding principle of Marxism construction and Marxist theory, are an important support for realizing the great rejuvenation of the Chinese nation, are the value proposition of construction of socialist modernization, and the inevitable requirement to ensure civilized, harmonious, sustained and healthy development of Chinese society.

Establish the Encouraging Theoretical Evaluation Mechanism for Marxist Reform. In the new historical period, the Marxist reform and development is required not only to adhere to the advanced nature of politics, but also to ensure the encouragement of economic reform. To establish an encouraging theoretical evaluation mechanism for the Marxist reform is the basis for unremitting use of capitalism to solve the bottleneck of China's social development, and the innovation to stimulate people's enthusiasm to reform and develop. In the new era, with the rapid development of the Internet, people can accept a lot of different social thoughts. The establishment of the theoretical evaluation mechanism for Marxist reform is the guarantee to constantly solve the disharmony in Marxist reform and innovation. In the course of combining the development of Marxism and China's revolution and the process of reform and opening-up, in order to understand the laws of Chinese society development, understand the fate and future of the country and understand our own social responsibility, we should confirm the theme of Marxist theoretical innovation. We can, by means of the theoretical evaluation mechanism, help people unify the revolutionary and scientific nature of Marxism, establish a relatively strict system, understand the Marxist scientific world outlook and methodology, maintain a clear political stand, struggle with enemies, combine the important theory of Marxism and reality and advocate the socialist social ideal, combining the basic stand and important thought of Marxism with construction of theoretical evaluation mechanism for the development of communism.

\section{Conclusion}

Marxist development concept is to develop new ideas as the guidance for social development, continuously promote institutional innovation and scientific and technological reform in China, and deepen the theme of Marxist theoretical innovation. We need to apply the Marxist development concept in the field of politics, economy, culture, and science and technology etc., and positively promote social development of China according to the Marxist guiding ideology.

\section{References}

[1] Zhang SX. A Study on the Problems and Countermeasures of Ideological and Political Education of College Students from the Perspective of Marxist Humanity [D]. Hebei Normal University, 2016.

[2] Chu ZY. The Historical Logic and Contemporary Construction of Chinese Marxist Theory Innovation Paradigm [D]. Anhui University,2014.

[3] Liu Y. Research on the Development of Chinese Communist Party 's Marxist Theory Education since the Reform and Opening-up [D]. Shandong University,2013.

[4] Jian X. A Study on the Motive Force and Mechanism of the Innovation of Marxism in China since the Reform and Opening-up [D]. Northeast Normal University,2013. 
[5] Zhang SZ. A Study of Marxist Ideology Theory in China [D]. Nanjing Normal University,2012.

[6] Shen WJ. A Study on the Political Function and Realization of Marxist Ideology [D]. Hebei Normal University,2012.

[7] Xu QC. A Study on the Traditional Cultural Basis of the Theoretical System of Socialism with Chinese Characteristics [D]. Shandong University,2012.

[8]Yu HX. A Comparative Study of Marxist Ruling Party 's reform [D]. Shandong University,2012.

[9] Hu ZL. Professor Zhao Yao 's Academic Achievements in the Leadership of Scientific Socialism in China [J]. Scientific Socialism,2012,(01):151-156.

[10] Cao JH. A Study on the Transformation of Marxist State Theory Paradigm [D]. University of Electronic Science and Technology of China,2011.

[11] Wu JQ. Reflections on the Teaching Reform and Innovation of Marxist Political Theory Course in Colleges and Universities [J]. Journal of Educational Science of Hunan Normal University,2007,(03):116-118.

[12] Hui HY. Research on Deng Xiaoping 's View of Development and Contemporary China' s Reform [D]. Xi'an University of Science and Technology,2003. 